Original

\title{
Laminin-1 acts as an adhesive for odontoblast-like cells and promotes their differentiation toward a hard tissue-forming phenotype
}

\author{
Jia Tang1) and Takashi Saito ${ }^{2)}$ \\ 1)Division of Biochemistry, Department of Oral Biology, School of Dentistry, \\ Health Sciences University of Hokkaido, Ishikari, Japan \\ 2)Division of Clinical Cariology and Endodontology, Department of Oral Rehabilitation, School of Dentistry, \\ Health Sciences University of Hokkaido, Ishikari, Japan
}

(Received August 4, 2017; Accepted September 1, 2017)

\begin{abstract}
The present study was designed to investigate the effect of laminin-1 (LN-1 or LN-111) on an odontoblast-like cell line, MDPC-23. Wells of nontreated polystyrene plates were coated with various concentrations of $\mathrm{LN}-1(0.1,1,10$, and $100 \mu \mathrm{g} / \mathrm{mL})$ and left to dry for 2 days. Water-coated surfaces were used as controls. MDPC-23 cell proliferation, differentiation and mineralization were evaluated in terms of the CCK-8 assay, ALP activity, real-time RT-PCR and Alizarin red staining. The data indicated that LN-1 promoted the proliferation of MDPC-23 cells in a concentration-dependent manner. Moreover, it enhanced ALP activity and expression of key odontogenic genes (DMP-1 and DSPP) upon addition of mineralization reagents, leading to significant promotion of calcification by the cells. These results demonstrate that $\mathrm{LN}-1$ acts as an adhesive for odontoblast-like cells, allowing up-regulation of odontogenic genes and accelerating matrix mineralization. In the context of the present study, the optimal LN-1 coating concentration for MDPC-23 cells was suggested to be $100 \mu \mathrm{g} / \mathrm{mL}$.
\end{abstract}

Correspondence to Dr. Jia Tang, Division of Biochemistry, Department of Oral Biology, School of Dentistry, Health Sciences University of Hokkaido, Kanazawa 1757, Tobetsu, Ishikari, Hokkaido 061-0293, Japan

E-mail: mathlover2004@163.com

J-STAGE Advance Publication: April 16, 2018

Color figures can be viewed in the online issue at J-STAGE.

doi.org/10.2334/josnusd.17-0286

DN/JST.JSTAGE/josnusd/17-0286
Keywords: laminin; adhesive; hard tissue; odontoblastlike cell.

\section{Introduction}

Laminins (LNs) are a family of conserved, multi-domain trimeric basement membrane (BM) proteins that contain an $\alpha$ chain, $\beta$ chain, and $\gamma$ chain. The LNs are named according to their chain composition, LN-1 possessing $\alpha 1, \beta 1$, and $\gamma 1$ chains, whereas $\mathrm{LN}-511$ possesses $\alpha 5, \beta 1$, and $\gamma 1$ chains, and so on. To date, five $\alpha$ (1-5), three $\beta$ (1-3), and three $\gamma$ (1-3) chains have been identified, giving rise to 16 distinct $\mathrm{LN}$ isoforms in mammals. Each isoform is expressed in a tissue- and developmental stage-specific manner, exerting its functions through binding with integrins (1). The LN family is an indispensable part of the structural scaffold in almost every tissue of an organism and contributes to preserving the structural integrity of the extracellular matrix, thus influencing the behavior of specific cells, including adhesion (2), proliferation (3), migration (4), and differentiation (5). Furthermore, LNs play an important role in neurite outgrowth: isoleucine-lysine-valine-alanine-valine (IKVAV) derived from the $\mathrm{LN} \alpha 1$ chain is a promising candidate that could be applicable for regeneration of neurons (6-8). Functional studies using knockout mice have revealed the essential roles of LN-1 in embryonic development: although LN-511 partially compensates for the function of LN-1 in embryos lacking the $\alpha 1$ chain, such mice show disappearance of Reichert's membrane and die by E7; similarly, mice lacking the $\beta 1$ chain have 
no BM and die within E5.5; embryos that are deficient in the $\gamma 1$ chain die within a day of implantation (9).

LNs have a molecular mass of $850 \mathrm{kDa}$ and their concentration in human serum fluctuates between 0.81 $\mu \mathrm{g} / \mathrm{mL}$ and $1.43 \mu \mathrm{g} / \mathrm{mL}$ (10). Tooth development is a complex process involving reciprocal interactions between the mesenchyme and the ectoderm. Like fibronectin (FN), LN-1 is synthesized by the tooth germ mesenchyme (11), and is detectable in the BM at the onset of cusp formation (12). LN is located in the inner and outer epithelia of the enamel organ, small blood vessels in the dental papilla, and the stellate reticulum of the rat first molar tooth germ (13). Using in situ hybridization, Salmivirta et al. have detected the $\alpha 1$ transcript in dental mesenchyme throughout embryonic tooth development. At postnatal day 1 in mice, expression was found to persist in polarized odontoblasts but not in secretory odontoblasts. Additionally, the presence of $\alpha 2$ and $\alpha 4$ mRNA expression was also confirmed in the tooth mesenchyme, whereas the $\alpha 3$ and $\alpha 5$ chains were found to be expressed in the epithelium (14). Thereafter, fibroblasts isolated from human tooth pulp were shown to produce LN $\beta 1$ and $\gamma 1$ transcripts (15). The early appearance of LN-1 in tooth germ indicates that it likely has roles in the process of tooth germ development. Although it has been reported that $\mathrm{LN}$ is effective in promoting the adhesion and differentiation of a number of other cell types (16), its roles in the MDPC-23 cell line, a type of odontoblast-like cell, remain elusive. Importantly, the specific effects of matrix proteins depend largely on cell type and experiment design, and therefore their appropriate concentrations must be established for each specific cell type. The present study was hence designed to determine the optimal coating concentration of LN-1 for eliciting the proliferation and differentiation of MDPC-23 cells.

\section{LN-1 coating}

\section{Materials and Methods}

LN-1 (1 mg/mL, L2020, Sigma, St. Louis, MO, USA) purified from Engelbreth-Holm-swarm murine sarcoma BM was purchased from Sigma Co. LN-1, stored at $-30^{\circ} \mathrm{C}$, was slowly thawed at $4^{\circ} \mathrm{C}$ in a refrigerator overnight to avoid formation of a gel. The protein was then serially diluted in ultra-pure distilled water (10977-015, Gibco, Grand Island, NY, USA) to $0.1,1,10$, and $100 \mu \mathrm{g} /$ $\mathrm{mL}$. These various concentrations were poured into nontreated polystyrene multi-well plates (96-well plate: 50 $\mu \mathrm{L} /$ well; 24-well plate: $200 \mu \mathrm{L} /$ well; and 12-well plate: $400 \mu \mathrm{L} /$ well). The plates were then left to dry with their lids open on a clean bench for two days. Wells coated with ultra-pure water and left to dry served as non-coated controls.

\section{Cell culture}

Mouse dental papilla cells-23 (MDPC-23), an odontoblast-like cell line, were kindly provided by Prof. Jacques E. Nör, School of Dentistry, University of Michigan. The cryopreserved MDPC-23 cells were thawed, and then grown in a $100-\mathrm{mm}$ plate (3020-100, Iwaki, Tokyo, Japan) for continuous passaging in maintenance medium comprising Dulbecco's modified Eagle medium (DMEM, D5796, Sigma, Dorset, UK) supplemented with 5\% fetal bovine serum (FBS, 10270-106, Gibco). The medium was changed every other day and the cells were detached using TrypLE Express Enzyme (12605-010, Gibco). Cultures were maintained at $37^{\circ} \mathrm{C}$ in a humidified atmosphere containing $95 \%$ air and $5 \% \mathrm{CO}_{2}$.

\section{Microscopic observation of cell morphology}

LN-1 was coated on a 24-well plate (1820-024, Iwaki) as described above. MDPC-23 cells were seeded into LN-1coated or non-coated control wells at a density of $1 \times 10^{4} /$ $\mathrm{mL}$ (culture media: $1 \mathrm{~mL} /$ well) in DMEM supplemented with 5\% FBS. Photographs of cells were taken using a phase contrast microscope (Olympus, Tokyo, Japan) at 1 $\mathrm{h}$ and $24 \mathrm{~h}$, respectively.

\section{Cell proliferation}

MDPC-23 cells were seeded into LN-1-coated or noncoated control wells at a density of $5 \times 10^{3} / \mathrm{mL}(100 \mu \mathrm{L} /$ well, 96-well plate, 351172, Falcon, MA, USA) in DMEM supplemented with 5\% FBS. Moreover, to eliminate the influence of background absorbance, culture medium was added to wells without cells to make a blank group. Cell counting kit-8 (CCK-8, Dojindo, Kumamoto, Japan) reagent was added on days one, two, four and six. After addition of CCK-8 (10 $\mu \mathrm{L} /$ well $)$, the cells were incubated at $37^{\circ} \mathrm{C}$ for $105 \mathrm{~min}$, and the absorbance was read at a wavelength of $450 \mathrm{~nm}$ in an iMark microplate reader (Bio-Rad, Hercules, CA, USA).

\footnotetext{
Alkaline phosphatase (ALP) activity

MDPC-23 cells were seeded into LN-1-coated or non-coated control wells at a density of $1.25 \times 10^{4} / \mathrm{mL}$ ( $2 \mathrm{~mL} /$ well, 12-well plate, 351143, Falcon) in DMEM supplemented with 5\% FBS. The medium was changed every other day until day four, and then the maintenance medium was replaced with mineralization reagent (MR) comprising $100 \mathrm{nM}$ dexamethasone (Dex, D2915, Sigma), $50 \mu \mathrm{g} / \mathrm{mL}$ ascorbic acid (AA, 013-19641, Wako, Japan), and $10 \mathrm{mM} \beta$-glycerophosphate ( $\beta$-GP,
} 
Table 1 Primer sequences, fragment sizes and annealing temperature

\begin{tabular}{llllc}
\hline Gene name & Forward (5' to 3') & Backward (5' to 3') & Fragment size (bp) & $\mathrm{T}_{\mathrm{m}}$ \\
\hline DMP-1 & CGTTCCTCTGGGGGCTGTCC & CCGGGATCATCGCTCTGCATC & 577 & 60 \\
DSPP & TCAATGGCGGGTGCTTTAGA & TGCTCACTGCACAACATGAAGA & 111 & 62 \\
OPN & TTTCCCTGTTTCTGATGAACAGTAT & CTCTGCTTATACTCCTTGGACTGCT & 228 & 55 \\
BSP & CTGCTTTAATCTTGCTCTG & CCATCTCCATTTTCTTCC & 211 & 55 \\
ALP & GGAAGGAGGCAGGATTGACCAC & GGGCCTGGTAGTTGTTGTGAGC & 338 & 55 \\
OCN & AGCTCAACCCCAATTGTGAC & AGCTGTGCCGTCCATACTTT & 190 & 55 \\
ITGA1 & TCAACGTTAGCCTCACCGTC & CAGGGATCGTCTCATTGGCA & 396 & 59.9 \\
ITGA3 & GAAAGGCTGACCGACGACTA & TGCGTGGTACTTGGGCATAA & 108 & 66 \\
ITGA5 & GAAGGGACGGAGTCAGTGTG & TGAATGGTGCTGCACTGGAT & 127 & 56 \\
ITGB1 & ACAAGAGTGCCGTGACAACT & AGCTTGATTCCAAGGGTCCG & 325 & 59.9 \\
$\beta$-actin & AACCCTAAGGCCAACAGTGAAAAG & TCATGAGGTAGTCTGTGAGGT & 241 & 53 \\
\hline
\end{tabular}

191-02042, Wako). On day six, the culture medium was aspirated, and the cells were washed gently with phosphate-buffered saline (PBS) before detachment using a cell scraper (99002, TPP, Trasadingen, Switzerland). The cells were then lysed with Triton-X-100 $(0.1 \%$ in distilled water) (T8787, Sigma) for $30 \mathrm{~s}$ and sonicated for $10 \mathrm{~min}$ on ice. The supernatant was collected after centrifugation and assayed using an ALP activity kit (Wako). Briefly, the sample was diluted 300 -fold in distilled water, added to a 96 -well plate $(20 \mu \mathrm{L} /$ well), and mixed with 100 $\mu \mathrm{L}$ of working assay solution ( $p$-nitrophenylphosphate disodium, $6.7 \mathrm{mmol} / \mathrm{L}$ ) in a plate mixer for $1 \mathrm{~min}$, then incubated at $37^{\circ} \mathrm{C}$ for $15 \mathrm{~min}$. After the reaction, stop solution (sodium hydroxide, $0.2 \mathrm{~mol} / \mathrm{L}$ ) was added to each well to terminate the reaction $(80 \mu \mathrm{L} /$ well). The plate was again shaken in a plate mixer for $1 \mathrm{~min}$ and the absorbance at $405 \mathrm{~nm}$ was read using a plate reader (Bio$\mathrm{Rad})$. The protein concentration was determined using a Pierce BCA protein assay kit (Thermo Fisher Scientific, Waltham, MA, USA). The final ALP activity (units/ $\mu \mathrm{g}$ protein) was determined as: $\frac{\text { calculated ALP activity }}{\text { Protein concentration }}$.

\section{Real-time reverse transcription-polymerase chain reaction (RT-PCR)}

Levels of odontoblastic gene expression in the noncoated and LN-1-coated groups were determined by real-time RT-PCR on day seven. Total RNA was isolated from the cultured cells using Trizol reagent (15596-018, Thermo Fisher Scientific), and the RNA concentration was measured by NanoDrop 1000 (ND-1000, Thermo Fisher Scientific). Complementary DNA (cDNA) was synthesized from $1 \mu \mathrm{g}$ of total RNA using M-MLV reverse transcriptase (28025-013, Invitrogen, Carlsbad, CA, USA), and the resulting cDNA was analyzed by realtime PCR using an SYBR green FastStart Essential DNA Green Master kit (6402712, Roche, Basel, Switzerland). The reaction was performed in a total volume of $20 \mu \mathrm{L}$ containing $10 \mu \mathrm{L}$ FastStart Essential DNA Green Master, $7 \mu \mathrm{L}$ PCR grade water (Roche), $1 \mu \mathrm{L}$ forward primer (final concentration: $500 \mathrm{nM}$ ), $1 \mu \mathrm{L}$ reverse primer (final concentration: $500 \mathrm{nM}$ ) and $1 \mu \mathrm{L}$ cDNA. The real-time PCR assay was performed using a LightCycler nano instrument (Roche). The reaction consisted of initial denaturation at $95^{\circ} \mathrm{C}$ for $10 \mathrm{~min}$, and 55 cycles of amplification $\left(95^{\circ} \mathrm{C}\right.$ for $15 \mathrm{~s}$, annealing (for temperatures please refer to Table 1) for $30 \mathrm{~s}$, and extension at $72^{\circ} \mathrm{C}$ for 40 $\mathrm{s})$. The calculated values of target gene expression were normalized to that of beta-actin ( $\beta$-actin), the internal control. Primer sequences are listed in Table 1.

\section{Alizarin red staining}

MDPC-23 cells were cultured in a 12-well plate at a density of $1.25 \times 10^{4} / \mathrm{mL}$ (culture media: $2 \mathrm{~mL} /$ well) in DMEM supplemented with 5\% FBS. The medium was changed every other day until day 4 , and then the maintenance medium was replaced with MR. To visualize the mineralization of cells, Alizarin red (AR) staining was conducted on day seven. Briefly, cells were rinsed twice with PBS and fixed with $10 \%$ neutral buffered formalin (060-01667, Wako) for $20 \mathrm{~min}$. Prior to staining, the cells were washed briefly with distilled water to remove excess fixative. Subsequently, AR solution (1\%, pH 4.1 in water) (011-01192, Wako) was poured into each well ( $400 \mu \mathrm{L} /$ well) and the cells were stained for about $5 \mathrm{~min}$ at room temperature. The AR solution was then aspirated and the cell monolayer was washed with distilled water for $2 \mathrm{~h}$. Finally, the stained cells were photographed using an inverted digital camera (Canon, Tokyo, Japan). To quantify the staining intensity, cetylpyridinium chloride (CPC, C0732-100G, Sigma) was added to each well (2 $\mathrm{mL} /$ well in 12-well plate) and incubation was carried out for $2 \mathrm{~h}$ at $37^{\circ} \mathrm{C}$. After incubation, the transparent CPC turned purple and was transferred to a new 96-well plate (200 $\mu \mathrm{L} /$ well) for reading of the absorbance at $570 \mathrm{~nm}$. 
A
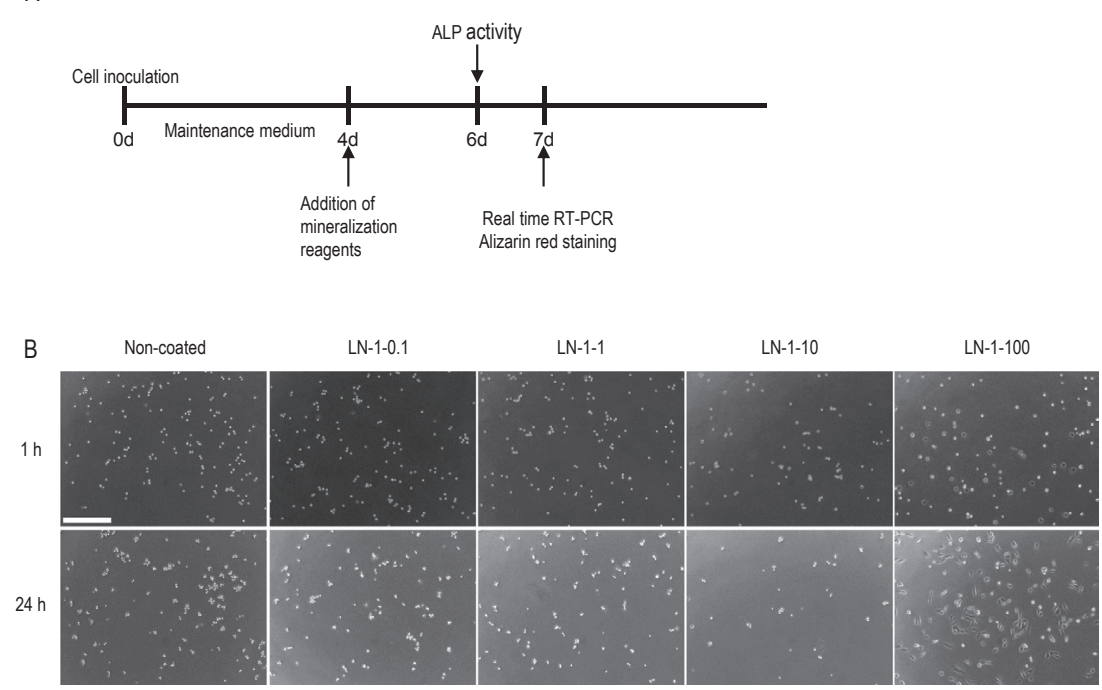

Fig. 1 Experiment timeline and cell morphology. A: Schematic illustration of the experiment timeline. Maintenance medium: DMEM supplemented with 5\% FBS; Mineralization reagent: dexamethasone (100 $\mathrm{nM}), \beta$-glycerophosphate $(10 \mathrm{mM})$, ascorbic acid $(50 \mu \mathrm{g} / \mathrm{mL})$. B: Cell morphology observation. LN-1 was coated on 24-well plates at concentrations of 0.1 (LN-1-0.1), 1 (LN-1-1), 10 (LN-1-10), and $100 \mu \mathrm{g} / \mathrm{mL}$ (LN-1-100). MDPC-23 cells were seeded into 24 -well plates at an initial number of $1 \times 10^{4} /$ well. Representative photomicrographs of cells are shown at $1 \mathrm{~h}$ and $24 \mathrm{~h}$ post-inoculation (scale bar: $400 \mu \mathrm{m}$ ).

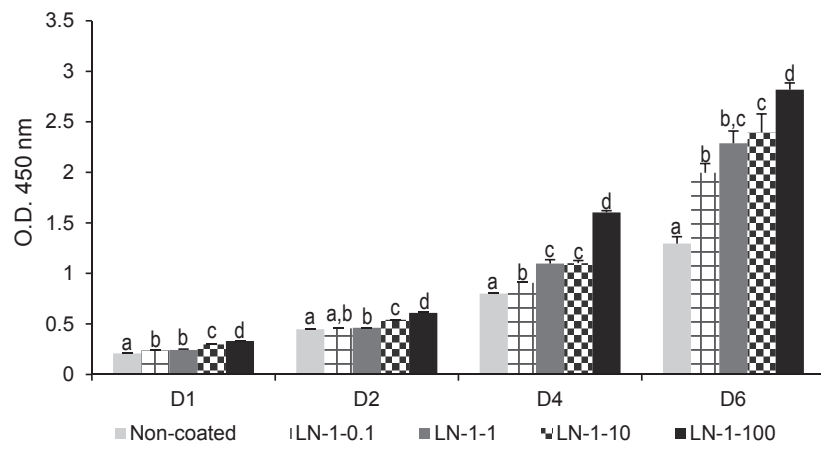

Fig. 2 Growth stimulation by the insoluble form of LN-1. MDPC-23 cells were inoculated on 96-well plates pre-coated with $\mathrm{LN}-1$ at various concentrations. After addition of CCK-8 reagent on day 1 (D1), day 2 (D2), day 4 (D4) and day 6 (D6), the absorbance of cells in each group was determined using a plate reader. Different characters represent significant differences on specific days, $P<0.01$ except for $P<0.05$ between Non-coated and LN-1-1 on D2, and LN-1-0.1 and LN-1-10 on D6.

\section{Statistical analysis}

The data were analyzed by post hoc Tukey HSD test. Differences were considered to be statistically significant at $P<0.05$.

\section{Results}

\section{Observation of cell morphology}

The specimens examined were divided into five separate groups: non-coated, LN-1 $0.1 \mu \mathrm{g} / \mathrm{mL}$ (LN-1-0.1), LN-1 1 $\mu \mathrm{g} / \mathrm{mL}$ (LN-1-1), LN-1 $10 \mu \mathrm{g} / \mathrm{mL}$ (LN-1-10), and LN-1 $100 \mu \mathrm{g} / \mathrm{mL}$ (LN-1-100). One hour after inoculation, cells

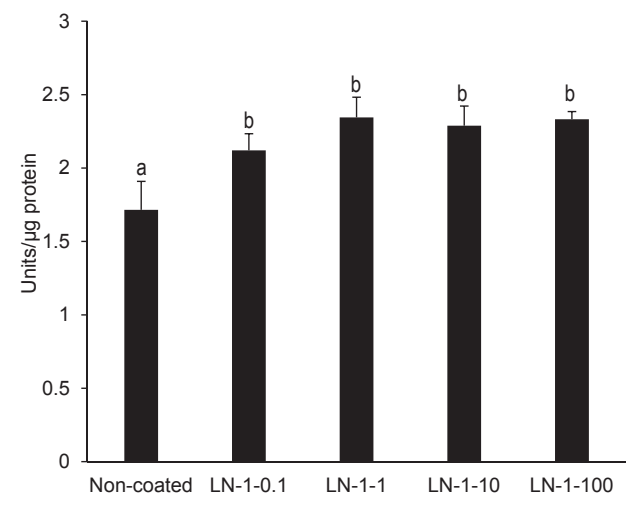

Fig. 3 Adhesion of MDPC-23 cells to LN-1 increases odontogenic-specific marker-ALP activity. MDPC-23 cells were plated for 6 days as indicated, and then assayed for ALP activity. Different characters represent significant differences at $P<0.01$, except for the difference between non-coated and LN-1-0.1, which was $P<0.05$.

remained spherical in shape in all of the groups except LN-1-100, in which some cells started attaching and forming protrusions (Fig. 1: $1 \mathrm{~h}$ ). As time increased up to $24 \mathrm{~h}$, cells cultured in LN-1-100 continued to spread and became spindle-shaped and flat, whereas cells in the other four groups remained round and exhibited no spreading (Fig. 1: $24 \mathrm{~h}$ ).

\section{Cell proliferation}

The effect of adsorbed LN-1 on the proliferation of MDPC-23 cells over a period of 6 days in culture is 

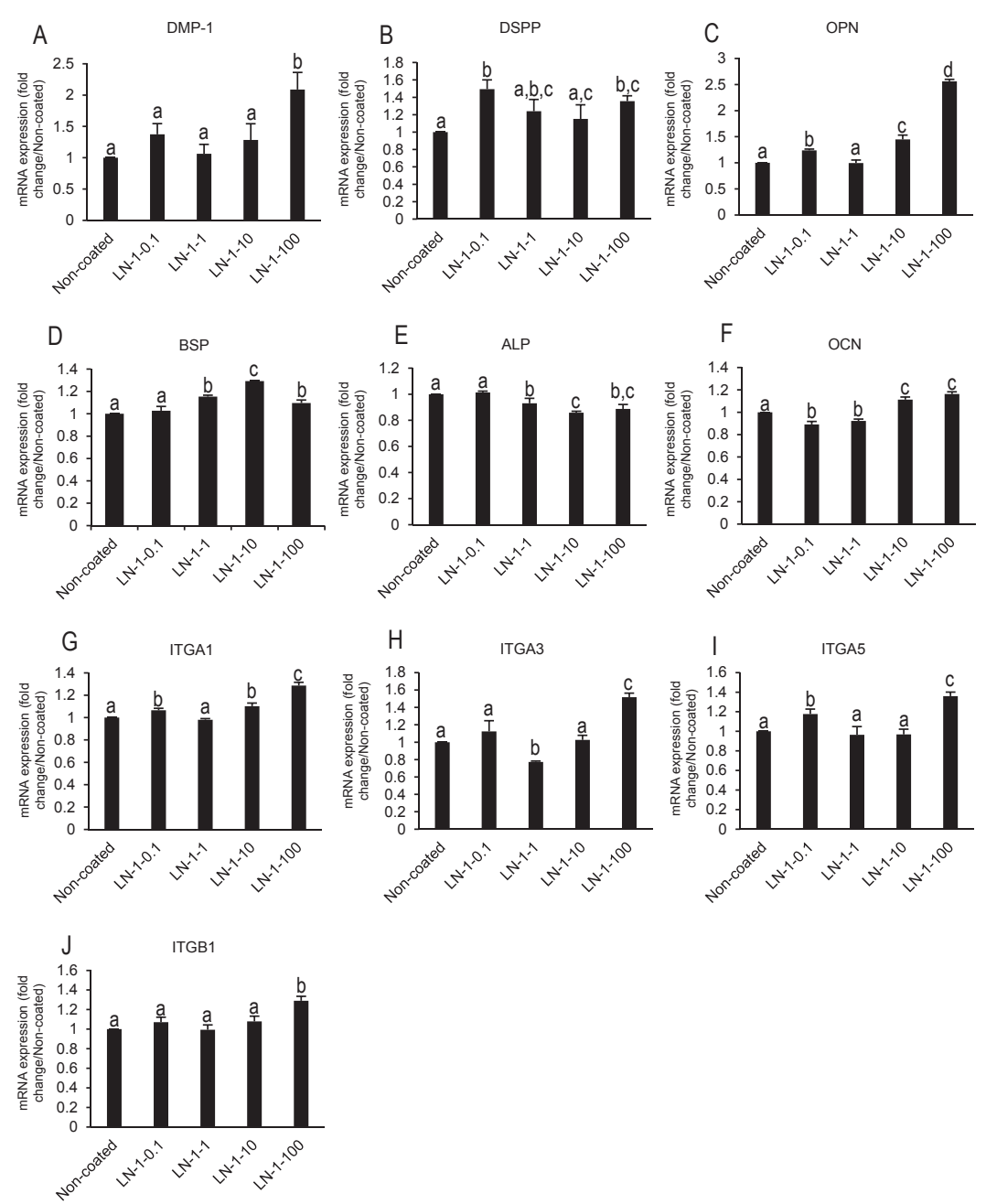

Fig. 4 Effects of LN-1 on odontogenic differentiation potential of MDPC-23 cells. MDPC-23 cells were cultured in a 12-well plate precoated with LN-1 at $0.1,1,10,100 \mu \mathrm{g} / \mathrm{mL}$, or uncoated (control). The cells were harvested on day 7 for isolation of RNA. Ten genes were analyzed using real-time RT-PCR to determine their individual expression levels upon LN-1 treatment. Different characters represent significant differences in each panel at $P<0.05$.

shown in Fig. 2. Cell proliferation showed a tendency to increase not only with time but also with concentration. Notably, a coating concentration of $100 \mu \mathrm{g} / \mathrm{mL}(0.33$ versus 0.21 for Non-coated on D1 $(P<0.01) ; 0.61$ versus 0.45 for Non-coated on D2 $(P<0.01) ; 1.60$ versus 0.80 for Non-coated on D4 $(P<0.01) ; 2.82$ versus 1.30 for Non-coated on D6 $(P<0.01))$ resulted in the highest cell proliferative activity on each day of observation.

\section{ALP activity}

MDPC-23 cells were cultured with LN-1 for 6 days. Specifically, the ALP activity in the various groups was as follows: Non-coated, $1.72 \pm 0.19$ units/ $\mu \mathrm{g}$ protein; LN-1-0.1, $2.12 \pm 0.11$ units/ $\mu$ g protein; LN-1-1, 2.35 \pm 0.14 units/ $\mu \mathrm{g}$ protein; $\mathrm{LN}-1-10,2.29 \pm 0.13$ units $/ \mu \mathrm{g}$ protein; LN-1-100, $2.33 \pm 0.05$ units/ $\mu \mathrm{g}$ protein. ALP activity was significantly augmented on day 6 in all of the LN-1 groups compared with the control (Fig. 3).
Meanwhile, no differences were detected among the four LN-1 groups.

\section{Real-time RT-PCR}

Levels of dentin matrix protein 1 (DMP-1), dentin sialophosphoprotein (DSPP), osteopontin (OPN), bone sialoprotein (BSP), alkaline phosphatase (ALP), osteocalcin (OCN), integrin $\alpha 1$ (ITGA1), integrin $\alpha 3$ (ITGA3), integrin $\alpha 5$ (ITGA5), and integrin $\beta 1$ (ITGB1) mRNA in the presence or absence of LN-1 were assessed by realtime RT-PCR analysis (Fig. 4). Significant upregulation of DMP-1 (2.09 \pm 0.27$)$ (Fig. 4A), DSPP $(1.36 \pm 0.06)$ (Fig. 4B), OPN (2.56 \pm 0.04$)$ (Fig. 4C), ITGA3 (1.52 \pm $0.05)$ (Fig. 4H), and ITGA5 (1.36 \pm 0.04$)$ (Fig. 4I) was observed on day 7 in the LN-1-100 group relative to the control. Expression of BSP (1.10 \pm 0.03$)$ (Fig. 4D), OCN $(1.16 \pm 0.02)$ (Fig. 4F), ITGA1 (1.29 \pm 0.03$)$ (Fig. 4G), and ITGB1 (1.29 \pm 0.04$)$ (Fig. 4J) was mildly enhanced 

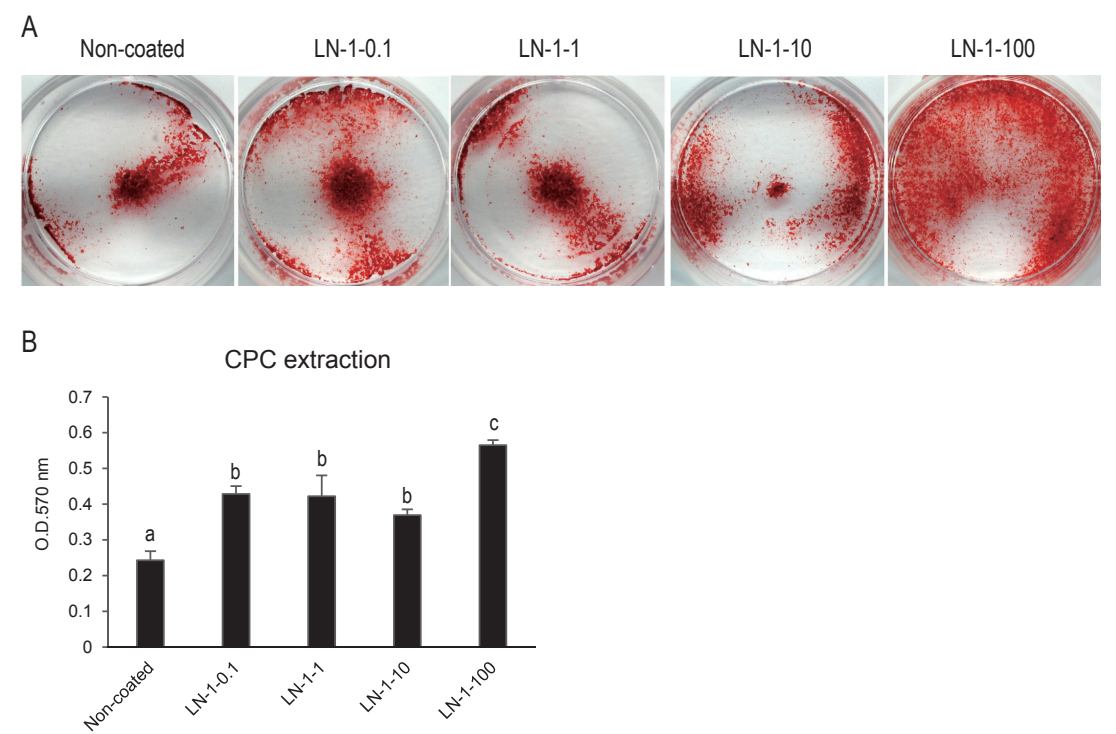

Fig. 5 Alizarin red staining. MDPC-23 cells were cultured on a 12-well plate precoated with LN-1 at 0.1, $1,10,100 \mu \mathrm{g} / \mathrm{mL}$, or uncoated (control). The cells were induced to undergo odontogenic differentiation on day 4, as described in Materials and Methods. The degree of differentiation was determined by Alizarin red staining (A) and CPC extraction (B). B: Different characters represent significant differences at $P<0.01$.

by LN-1-100, whereas ALP was slightly downregulated (Fig. 4E).

\section{Alizarin red staining}

In order to evaluate the effects of LN-1 on promotion of a mature odontoblast phenotype, AR staining was conducted on day 7 (Fig. 5). As clearly shown in Fig. $5 \mathrm{~A}$, intense staining of a calcific matrix was detected in the LN-1-100 group (Fig. 5A), and CPC extraction of the stain further confirmed a 2.4-fold increase of mineralization in the LN-1-100 group relative to the control (Fig. 5B). In the other three LN-1 groups, the mineralization of MDPC-23 cells was also promoted, although to a lesser extent than in the LN-1-100 group.

\section{Discussion}

LNs are heterotrimeric glycoproteins of the BM. LN-1 is the major LN expressed at an early stage of mouse embryogenesis. The inhibitory effect of LN-1 and tenascin on osteoprogenitor attachment has already been documented (17). However, in the present study, markedly higher cell proliferation activities were found to persist for 6 days on LN-1-coated substrates (0.1-100 $\mu \mathrm{g}$ / $\mathrm{mL}$ ), and the concentration of $100 \mu \mathrm{g} / \mathrm{mL}$ appeared to be the one eliciting the strongest cell proliferative activity. Our proliferation data correlate well with a study by Fujita et al., who revealed that $\mathrm{LN}-1(400 \mu \mathrm{g} / \mathrm{mL}$ and $800 \mu \mathrm{g} / \mathrm{mL}$ ) physically adsorbed onto hydroxyapatite promoted the proliferation of MC3T3-E1 (18), an osteoblast-like cell line. Furthermore, as shown in Fig. 1, cells in the LN-1 $100 \mu \mathrm{g} / \mathrm{mL}$ group underwent flattening and spreading at a much earlier stage. This flattened shape led to a reduction of cell height and an increase in the area of cell contact, which in turn further promoted the binding of cells to substrate ligands. Our results revealed that a coating concentration of $100 \mu \mathrm{g} / \mathrm{mL}$ was optimal for achieving early flattening and spreading of MDPC-23 cells, although lower concentrations $(0.1-10 \mu \mathrm{g} / \mathrm{mL})$ also resulted in significantly higher cell proliferative activity. With the passage of time, cells in the other concentration groups also spread, but less rapidly than those in the LN-1 $(100 \mu \mathrm{g} / \mathrm{mL})$ group. Early cell spreading and flattening was observed only in wells coated with 100 $\mu \mathrm{g} / \mathrm{mL} \mathrm{LN}-1$, far exceeding the concentration of fibronectin $(\mathrm{FN}, 10 \mu \mathrm{g} / \mathrm{mL})$ that is necessary to achieve the same effect (19). These results revealed that LN-1 is less adhesive than FN, as a significantly higher concentration of LN-1 was needed to achieve a comparable degree of cell adhesion. One possible explanation might be that although LN-1 contains binding ligands for integrin receptors, MDPC-23 cells do not express the receptors specific for LN-1. Furthermore, the orientation of LN-1 molecules on the surface after coating may change, thus decreasing the accessibility of the integrin binding sites. Indeed, it has already been clarified that human bone cells bind preferentially to FN and have low affinity for LN and collagen type V (20). In addition, Tabata et al. have compared the proliferation and differentiation of ameloblast lineage (AL) cells on type I collagen, FN, type IV collagen and $\mathrm{LN}-1$, and found that $\mathrm{FN}$ was the most 
potent extracellular matrix protein for facilitating $\mathrm{AL}$ cell proliferation in either low- or high-density culture, whereas AL cells showed no evident growth on LN-1 (11). In another study, human mesenchymal stem cells (hMSCs) were tested for their affinity for five matrix proteins, and LN-1 was shown to have the lowest affinity (FN $>$ type I collagen $>$ type IV collagen $>$ vitronectin $>$ LN-1) (21).

In the present study, the ALP activity of MDPC-23 cells cultured on LN-1 became maximal on day 6. ALP catalyzes the hydrolysis of phosphate esters (22) and is recognized to be an early marker of odonto/osteoblast differentiation. Our results showed that in the presence of mineralization reagents ( $\beta$-GP, AA, and Dex), LN-1 as an extracellular protein promoted the production of ALP and activated early odontogenic differentiation.

To further examine the role of LN-1 in MDPC-23 cell differentiation, real-time RT-PCR was performed to measure the gene expression levels of DMP-1, DSPP, OPN, BSP, ALP, and OCN after 7 days of incubation. Expression of DMP-1 and DSPP is known to be upregulated after stimulation of odontogenic differentiation (23). On day 7, MDPC-23 cells cultured on LN-1 exhibited significantly higher DMP-1 and DSPP expression than the controls. Furthermore, the level of OPN mRNA in cells cultured on LN-1 $(100 \mu \mathrm{g} / \mathrm{mL})$ was markedly promoted. These results are consistent with the data for ALP activity and calcification. In addition, we assessed the mRNA expression levels of BSP, ALP and OCN. In an earlier experiment, we had found that BSP was highly responsive to matrix proteins such as type I collagen and FN: coating with these two proteins elicited a dramatic increase of BSP expression (2-3-fold relative to the control) in MDPC-23 cells (19). In contrast, LN-1 coating of polystyrene wells resulted in only modest enhancement of BSP expression (1.15-fold in the LN-1-1 group, 1.29-fold in the LN-1-10 group, and 1.10-fold in the LN-1-100 group). Being members of the small integrin binding ligand N-linked glycoprotein (SIBLING) gene family, both DSPP and BSP are restrictively expressed in mineralizing tissues. Notably, DSPP is considered to be a marker of odontoblast differentiation and dentin tissue, as the proteolytic product of DSPP-dentin phosphophoryn (DPP) is the predominant component of non-collagenous proteins in dentin (24). On the other hand, BSP, originally isolated from bovine cortical bone, serves as a matrix-associated signal directly promoting osteoblast differentiation (25). It is a multifunctional extracellular matrix protein found in mineralized tissues such as bone, cartilage, cementum, and dentin. Knockout of BSP in mice has underlined its important roles in cementogenesis and intramembranous ossification, but not dentinogenesis (26). Given its presence in these three types of hard tissue, BSP is considered to be a marker for not only bone and cementum, but also dentin. In the present study, BSP expression was slightly elevated in cells cultured in LN-1 (1-100)-coated dishes, suggesting that LN-1 induced the differentiation of MDPC-23 cells into hard tissue-forming cells such as odontoblasts, cementoblasts, and osteoblasts. LN-1 exhibited only a marginal effect on the expression of OCN mRNA, as the degree of change in the LN-1-coated groups was less than 1.2-fold. Moreover, the expression of ALP was slightly down-regulated in the 1,10 , and $100 \mu \mathrm{g} / \mathrm{mLLN}-1$ groups. It is known that gene expression is strictly regulated in a spatio-temporal manner, and in the present study we conducted real-time RT-PCR only on day 7. Therefore, the expression of ALP mRNA may peak at an earlier time point and decrease thereafter. An investigation of gene expression at various time points will be needed in the future. Previously, Klees and colleagues tested the effects of LN-332 (LN-5) in hMSCs, and found that LN-5 activated the expression of mRNAs for ALP, OPN and OCN after 16 days of culture. This effect was inhibited in the presence of PD98059, a specific ERK inhibitor (27), indicating that the osteogenic effect of LN-5 was at least partially mediated through the ERK signaling pathway. Moreover, a study using a rabbit model demonstrated that ALP, OCN and Runx2 were upregulated by LN-1coated nanoroughened implants (16). The differences in results might have been due to the different cell types and experimental designs employed.

Integrins are known to mediate the signaling transduction, generating cross-talk between the extracellular matrix and cells, creating a unique and dynamic mechanosensitive microenvironment. Early spreading and accelerated mineralization of MDPC-23 cells on LN-1100 substrate suggested the possible robust involvement of integrins. It has been reported that integrins $\alpha 1 \beta 1$ and $\alpha 3 \beta 1$ serve as LN receptors in different cell types (28). Also, to test whether integrin $\alpha 5$, a well-known FN receptor, was influenced by LN-1, we quantified the mRNA expression levels of ITGA1, ITGA3, ITGA5, and ITGB1. We found that expression of ITGB1, a ubiquitous integrin, was enhanced by $100 \mu \mathrm{g} / \mathrm{mL} \mathrm{LN}-1$ on day 7. Previous studies have demonstrated that truncation of the cytoplasmic portion of ITGB1 or complete knockout of the protein reduced cell spreading and the formation of focal adhesion complexes. Other studies have further demonstrated that ITGB1 is critical for cell migration and differentiation. For example, Olivares-Navarrete et al. silenced ITGB1 in osteoblast-like cells and found 
that osteoblast maturation in response to surface architecture was impaired (29). Simultaneously, they showed that ITGA1 silencing decreased the amount of VEGF, suggesting that ITGA1 is involved in the creation of an angiogenic environment. ITGA1-knockout mice exhibit poorly vascularized tumors compared to wild-type mice, probably because of increased MMP9, which inhibits endothelial cell growth (30). In addition, we have also investigated the expression of ITGA3 and ITGA5. In comparison with ITGA1 and ITGA5, the expression of ITGA3 was promoted to the largest extent. A study to investigate the comparative affinity and specificity for different integrins revealed that integrins $\alpha 3 \beta 1$ and $\alpha 6 \beta 4$ have clear specificity for LN-5 and LN-511 (LN-10), and that although $\alpha 6 \beta 1$ showed broad binding specificity, it preferred to bind with LN-1, LN-5, LN-10, and LN-521 (LN-11) (31).

Finally, to investigate the effect of LN-1 on the mineralization capacity of MDPC-23 cells, Alizarin red staining was carried out to visualize calcification in cell monolayer culture. Synthesis of type I collagen matrix and mineralization of this fibrillar scaffold marks the terminal differentiation of odontoblasts (32). In the present study, we found that mineralization in MDPC-23 cells cultured on LN-1-coated substrates was dramatically enhanced, suggesting robust differentiation of cells in the presence of external induction factors. In particular, cells grown on $100 \mu \mathrm{g} / \mathrm{mL} \mathrm{LN-1} \mathrm{showed} \mathrm{the} \mathrm{strongest}$ staining, suggesting that a sufficient coating concentration of LN-1 is needed to achieve optimal mineralization. The mechanisms underlying the enhancement of mineralization may be attributable to several aspects. First, as shown above, cells proliferate rapidly on LN-1-coated surfaces, indicating that they reach confluence much earlier than untreated controls, and therefore undergo differentiation and mineralization much earlier as well. Second, the gene analysis data suggested that integrins such as ITGA1, ITGA3, ITGA5, and ITGB1 were all upregulated by LN-1, suggesting intensive binding and interaction between cells and the underlying LN-1, subsequently eliciting robust activation of intracellular signaling pathways. Furthermore, the higher mineralization level in the $100 \mu \mathrm{g} / \mathrm{mL} \mathrm{LN}-1$ group correlated well with the conclusion of an earlier study, i.e. that the surface density of ligands is an important determinant of extracellular matrix mineralization (33).

Our results have provided a novel insight into the in vitro effects of $\mathrm{LN}-1$ on odontoblast-like cells, leading to a better understanding of the function of LN-1 in tooth development. More importantly, our data suggest that $\mathrm{LN}-1$ could be a promising biocompatible material for use in dental tissue regeneration. Indeed, in vivo tests of LN-1 have been conducted to evaluate its potential use for integration of implants with alveolar bone: Bougas et al. demonstrated that LN-1-coated implants had a significant higher removal torque, and that the area of bone surrounding the implant was dramatically higher after 4 weeks, suggesting that LN-1 would have considerable potential for use as a coating agent for implant surface modification (34). However, due to differences in animal models and evaluation systems, in vivo results obtained using LN-1-coated implants vary from one group to another, and the in vivo conditions do not completely recapitulate the actual scenario in the human body. Hence, for more precise clinical evaluation of LN-1 as a coating for implants, more randomized control trials will be required (35).

To summarize, in the present work, we found that LN-1 potently stimulated the spreading and growth of MDPC-23 cells and promoted their odontogenic differentiation in culture. Furthermore, LN-1 strongly enhanced the calcific deposition of MDPC-23 cells in the presence of mineralization reagents ( $\beta-G P, A A$ and Dex). These results suggest that LN-1 may contribute to the development of dentin tissues by regulating the proliferation and differentiation of dental papilla-derived cells. The unique activities of LN-1 also suggest it may be a promising scaffold for dentin tissue engineering.

\section{Acknowledgments}

This work was supported by JSPS KAKENHI Grant Numbers JP15H05024 and JP17K17139.

\section{Conflict of interest}

None declared.

\section{References}

1. Yamada M, Sekiguchi K (2015) Molecular basis of lamininintegrin interactions. Curr Top Membr 76, 197-229.

2. Nomizu M, Kuratomi Y, Malinda KM, Song SY, Miyoshi K, Otaka A et al. (1998) Cell binding sequences in mouse laminin alphal chain. J Biol Chem 273, 32491-32499.

3. Kubota S, Tashiro K, Yamada Y (1992) Signaling site of laminin with mitogenic activity. J Biol Chem 267, 4285-4288.

4. Colucci S, Giannelli G, Grano M, Faccio R, Quaranta V, Zallone AZ (1996) Human osteoclast-like cells selectively recognize laminin isoforms, an event that induces migration and activates $\mathrm{Ca}^{2+}$ mediated signals. J Cell Sci 109, 15271535.

5. Rozzo C, Ratti P, Ponzoni M, Cornaglia-Ferraris P (1993) Modulation of $\alpha_{1} \beta_{1}, \alpha_{2} \beta_{1}$, and $\alpha_{3} \beta_{1}$ integrin heterodimers during human neuroblastoma cell differentiation. FEBS Lett 332, 263-267.

6. Cheng TY, Chen MH, Chang WH, Huang MY, Wang TW 
(2013) Neural stem cells encapsulated in a functionalized self-assembling peptide hydrogel for brain tissue engineering. Biomaterials 34, 2005-2016.

7. Sun W, Incitti T, Migliaresi C, Quattrone A, Casarosa S, Motta A (2017) Viability and neuronal differentiation of neural stem cells encapsulated in silk fibroin hydrogel functionalized with an IKVAV peptide. J Tissue Eng Regen Med 11, 1532-1541.

8. Hamsici S, Cinar G, Celebioglu A, Uyar T, Tekinay AB, Guler MO (2017) Bioactive peptide functionalized aligned cyclodextrin nanofibers for neurite outgrowth. J Mater Chem B 5, 517-524.

9. Miner JH, Li C, Mudd JL, Go G, Sutherland AE (2004) Compositional and structural requirements for laminin and basement membranes during mouse embryo implantation and gastrulation. Development 131, 2247-2256.

10. Gressner AM, Tittor W (1986) Serum laminin--its concentration increases with portal hypertension in cirrhotic liver disease. Klin Wochenschr 64, 1240-1248.

11. Tabata MJ, Matsumura T, Fujii T, Abe M, Kurisu K (2003) Fibronectin accelerates the growth and differentiation of ameloblast lineage cells in vitro. J Histochem Cytochem 51, 1673-1679.

12. Thesleff I, Barrach HJ, Foidart JM, Vaheri A, Pratt RM, Martin GR (1981) Changes in the distribution of type IV collagen, laminin, proteoglycan, and fibronectin during mouse tooth development. Dev Biol 81, 182-192.

13. Della CR, Veiga SS, Line SR (1997) Immunohistochemical and biochemical analysis of laminin in neonatal rat first molars. J Nihon Univ Sch Dent 39,176-181.

14. Salmivirta K, Sorokin LM, Ekblom P (1997) Differential expression of laminin $\alpha$ chains during murine tooth development. Dev Dyn 210, 206-215.

15. Fried K, Sime W, Lillesaar C, Virtanen I, Tryggvasson K, Patarroyo M (2005) Laminins $2(\alpha 2 \beta 1 \gamma 1, \mathrm{Lm}-211)$ and 8 $(\alpha 4 \beta 1 \gamma 1, \mathrm{Lm}-411)$ are synthesized and secreted by tooth pulp fibroblasts and differentially promote neurite outgrowth from trigeminal ganglion sensory neurons. Exp Cell Res 307, 329-341.

16. Schwartz-Filho HO, Bougas K, Coelho PG, Xue Y, Hayashi M, Faeda RS et al. (2012) The effect of laminin-1-doped nanoroughened implant surfaces: gene expression and morphological evaluation. Int J Biomater 2012, 305638.

17. Roche P, Goldberg HA, Delmas PD, Malaval L (1999) Selective attachment of osteoprogenitors to laminin. Bone 24, 329-336.

18. Fujita H, Kudo TA, Kanetaka H, Miyazaki T, Hashimoto M, Kawashita M (2016) Adsorption of laminin on hydroxyapatite and alumina and the MC3T3-E1 cell response. ACS Biomater Sci Eng 2, 1162-1168.

19. Tang J, Saito T (2017) Human plasma fibronectin promotes proliferation and differentiation of odontoblast. J Appl Oral Sci 25, 299-309.

20. Gronthos S, Stewart K, Graves SE, Hay S, Simmons PJ (1997) Integrin expression and function on human osteoblastlike cells. J Bone Miner Res 12, 1189-1197.

21. Salasznyk RM, Williams WA, Boskey A, Batorsky A, Plopper GE (2004) Adhesion to vitronectin and collagen I promotes osteogenic differentiation of human mesenchymal stem cells. J Biomed Biotechnol 2004, 24-34.

22. Stucki U, Schmid J, Hämmerle CF, Lang NP (2001) Temporal and local appearance of alkaline phosphatase activity in early stages of guided bone regeneration. A descriptive histochemical study in humans. Clin Oral Implants Res 12, 121-127.

23. Chen Z, Li W, Wang H, Wan C, Luo D, Deng S et al. (2016) K1f10 regulates odontoblast differentiation and mineralization via promoting expression of dentin matrix protein 1 and dentin sialophosphoprotein genes. Cell Tissue Res 363, 385-398.

24. Yamakoshi Y, Kinoshita S, Izuhara L, Karakida T, Fukae M, Oida S (2014) DPP and DSP are necessary for maintaining TGF- $\beta 1$ activity in dentin. J Dent Res 93, 671-677.

25. Gordon JA, Tye CE, Sampaio AV, Underhill TM, Hunter GK, Goldberg HA (2007) Bone sialoprotein expression enhances osteoblast differentiation and matrix mineralization in vitro. Bone 41, 462-473.

26. Foster BL, Ao M, Willoughby C, Soenjaya Y, Holm E, Lukashova L et al. (2015) Mineralization defects in cementum and craniofacial bone from loss of bone sialoprotein. Bone 78, 150-164.

27. Klees RF, Salasznyk RM, Kingsley K, Willliams WA, Boskey A, Plopper GE (2005) Laminin-5 induces osteogenic gene expression in human mesenchymal stem cells through an ERK-dependent pathway. Mol Biol Cell 16, 881-890.

28. Belkin AM, Stepp MA (2000) Integrins as receptors for laminins. Microsc Res Tech 51, 280-301.

29. Olivares-Navarrete R, Rodil SE, Hyzy SL, Dunn GR, Almaguer-Flores A, Schwartz Z et al. (2015) Role of integrin subunits in mesenchymal stem cell differentiation and osteoblast maturation on graphitic carbon-coated microstructured surfaces. Biomaterials 51, 69-79.

30. Macias-Perez I, Borza C, Chen X, Yan X, Ibanez R, Mernaugh $G$ et al. (2008) Loss of integrin $\alpha 1 \beta 1$ ameliorates Kras-induced lung cancer. Cancer Res 68, 6127-6135.

31. Nishiuchi R, Takagi J, Hayashi M, Ido H, Yagi Y, Sanzen N et al. (2006) Ligand-binding specificities of laminin-binding integrins: a comprehensive survey of laminin-integrin interactions using recombinant $\alpha 3 \beta 1, \alpha 6 \beta 1, \alpha 7 \beta 1$ and $\alpha 6 \beta 4$ integrins. Matrix Biol 25, 189-197.

32. Goldberg M, Kulkarni AB, Young M, Boskey A (2011) Dentin: structure, composition and mineralization: the role of dentin ECM in dentin formation and mineralization. Front Biosci (Elite Ed) 3, 711-735.

33. Rezania A, Healy KE (2000) The effect of peptide surface density on mineralization of a matrix deposited by osteogenic cells. J Biomed Mater Res 52, 595-600.

34. Bougas K, Jimbo R, Vandeweghe S, Tovar N, Baldassarri M, Alenezi A et al. (2014) In vivo evaluation of a novel implant coating agent: laminin-1. Clin Implant Dent Relat Res 16, 728-735.

35. Javed F, Al Amri MD, Kellesarian SV, Al-Askar M, Al-Kheraif AA, Romanos GE (2016) Laminin coatings on implant surfaces promote osseointegration: fact or fiction? Arch Oral Biol 68, 153-161. 